\title{
Análise da qualidade da água recreativa em balneários da Cidade de Açailândia, Maranhão, Brasil
}

\author{
Analysis of the quality of the recreational water in spas in the City of Açailândia, Maranhão, Brazil \\ Análisis de la calidad del agua recreativa en spas de la Ciudad de Açailândia, Maranhão, Brasil
}

Recebido: 26/09/2021 | Revisado: 04/10/2021 | Aceito: 09/10/2021 | Publicado: 11/10/2021

Carlos Alberto Andrade Serra dos Santos

ORCID: https://orcid.org/0000-0003-2436-3677

Universidade Estadual da Região Tocantina do Maranhão, Brasil

E-mail: carlos.santos@uemasul.edu.br

Luciene de Oliveira

ORCID: https://orcid.org/0000-0003-4617-5693

Universidade Estadual da Região Tocantina do Maranhão, Brasil

E-mail: lu12sophia.josio@gmail.com

Mikaely Alencar Barbosa

ORCID: https://orcid.org/0000-0003-2685-682X

Universidade Estadual da Região Tocantina do Maranhão, Brasil

E-mail: mickaellyalencar10@gmail.com

Tania Regina Zanella Horster

ORCID: https://orcid.org/0000-0001-6067-6465

Universidade Estadual da Região Tocantina do Maranhão, Brasil E-mail: taniarzanella@hotmail.com

Bruno Lucio Meneses Nascimento

ORCID: https://orcid.org/0000-0002-7196-6502

Universidade Estadual da Região Tocantina do Maranhão, Brasil

E-mail: bruno.nascimento@uemasul.edu.br

Maria Aparecida Alves de Oliveira Serra

ORCID: https://orcid.org/0000-0003-0952-9560

Universidade Federal do Maranhão, Brasil

E-mail: cidinhaenfaufc@yahoo.com.br

Ivo Almeida Costa

ORCID: https://orcid.org/0000-0002-9227-1240

Universidade Estadual da Região Tocantina do Maranhão, Brasil

E-mail: ivo.costa@uemasul.edu.br

Jose Fábio França Orlanda

ORCID: http://orcid.org/0000-0002-6402-6192

Universidade Estadual da Região Tocantina do Maranhão, Brasil

E-mail: fabiorlanda@yahoo.com.br

\begin{abstract}
Resumo
Desde as primeiras civilizações o homem busca se instalar sempre próximo a margens de rios, lagos e mares buscando suprir desde as necessidades básicas até as mais complexas. Essa relação do homem com a natureza é um assunto muito discutido atualmente, pois, a utilização dos recursos hídricos tem gerado graves impactos aos ecossistemas, poluição, contaminação e podendo culminar na escassez desse bem natural. O presente estudo teve como finalidade avaliar a qualidade da água recreativa em balneários banhados pelo córrego Mosquito da cidade de Açailândia- MA conforme os padrões de estabelecidos pela Portaria $n^{\circ} 888$ de 2021 do Ministério da Saúde (MS) as resoluções CONAMA $\mathrm{n}^{\circ}$ 274/2000 e $\mathrm{n}^{\circ}$ 357/2005. O levantamento inicial da área de estudo foi feito, utilizando georreferenciamento pela ferramenta exploratória Google Earth. O critério de escolha dos pontos amostrais se deu pelo motivo de serem os mais frequentados para atividade balneária recreativa no município. Foram realizados testes físico-químicos e microbiológicos pelas técnicas APHA, EPA, SM e FUNASA. De acordo com os resultados obtidos, a maioria dos parâmetros analisados em todos os pontos (P1, P2, P3 e P4), tais como como pH, índices de ferro, fósforo, nitrito e nitrato não se encontram em conformidade com a Portaria ${ }^{\circ}$ 888/2021 do MS além de altas concentrações de bactérias termotolerantes com concentração $\geq 1600 \mathrm{NMP} / 100 \mathrm{~mL}$ mostrando que possivelmente o corpo hídrico está poluído. Assim, a água em todos os pontos de coleta analisados não está apta para o contato primário tendo uma predominância de classe 3 .
\end{abstract}

Palavras-chave: Balneabilidade; Análise de água; Corpo de água; Saúde pública.

\section{Abstract}

Since the first civilizations, man has always sought to settle close to the banks of rivers, lakes, and seas, seeking to supply everything from basic to more complex needs. This relationship between man and nature is a subject that is 
currently being discussed since the use of water resources has generated serious impacts on ecosystems, pollution, contamination and may culminate in the scarcity of this natural good. This study aimed to evaluate the quality of recreational water in spas bathed by the Mosquito stream in the city of Açailândia-MA, according to the standards established by Ordinance No. 888 of 2021 of the Ministry of Health (MS) to CONAMA resolutions No. 274/2000 and No. 357/2005. The initial survey of the study area was carried out using georeferencing by the exploratory tool Google Earth. The criterion for choosing the sampling points was because they are the most frequented recreational bathing activities in the city. Physical-chemical and microbiological tests were performed using the APHA, EPA, SM, and FUNASA techniques. According to the results obtained, most of the parameters analyzed at all points (P1, P2, P3, and $\mathrm{P} 4$ ), such as $\mathrm{pH}$, iron, phosphorus, nitrite, and nitrate indices are not in accordance with Ordinance No. $888 / 2021$ of MS in addition to high concentrations of thermotolerant bacteria with concentration $\geq 1600 \mathrm{NMP} / 100 \mathrm{~mL}$ showed that the water body is possibly polluted. Thus, the water at all analyzed collection points is not suitable for primary contact, having a predominance of class 3 .

Keywords: Bathing; Water analysis; Body of water; Public health.

\section{Resumen}

Desde las primeras civilizaciones, el hombre siempre ha buscado asentarse cerca de las orillas de ríos, lagos y mares, buscando suplir desde las necesidades básicas hasta las más complejas. Esta relación entre el hombre y la naturaleza es un tema que se está discutiendo actualmente, ya que el uso de los recursos hídricos ha generado graves impactos en los ecosistemas, polución, contaminación y puede culminar en la escasez de este bien natural. Este estudio tuvo como objetivo evaluar la calidad del agua recreativa en los balnearios bañados por el arroyo Mosquito en la ciudad de Açailândia-MA, de acuerdo con los estándares establecidos por la Ordenanza No. 888 de 2021 del Ministerio de Salud (MS) a las resoluciones de CONAMA No. 274/2000 y No. 357/2005. El levantamiento inicial del área de estudio se realizó mediante la georreferenciación mediante la herramienta exploratoria Google Earth. El criterio para la elección de los puntos de muestreo fue que son los más frecuentados para actividades de baño recreativo en la ciudad. Se realizaron pruebas físico-químicas y microbiológicas utilizando las técnicas APHA, EPA, SM y FUNASA. De acuerdo con los resultados obtenidos, la mayoría de los parámetros analizados en todos los puntos (P1, P2, P3 y P4), como los índices de pH, hierro, fósforo, nitritos y nitratos no están de acuerdo con la Ordenanza N ${ }^{\circ} 888 / 2021$ de MS en además de altas concentraciones de bacterias termotolerantes con concentración $\geq 1600 \mathrm{NMP} / 100 \mathrm{~mL}$, lo que demuestra que el cuerpo de agua posiblemente esté contaminado. Así, el agua en todos los puntos de recogida analizados no es apta para contacto primario, teniendo predominio de clase 3.

Palabras clave: Baño; Análisis de agua; Cuerpo de agua; Salud pública.

\section{Introdução}

A água é um recurso finito e indispensável para a sobrevivência da humanidade e de várias outras espécies, assim, sua qualidade torna-se uma preocupação global, pois ela está inserida em diversas atividades, tais como, geração de energia, abastecimento público, produção industrial, produção agrícola (Santos et al., 2020), além de recreação e paisagismo (Zang et al., 2009; Dumanski \& Pieri, 2000).

Estudos relacionados à qualidade da água são necessários para conhecer o nível desse recurso natural e definir uma forma sustentável de seu uso (Shrestha \& Kazama, 2007). A poluição dos corpos de água nas áreas urbanas está associada ao contato com esgoto doméstico, parcialmente tratado ou não, resíduo industrial e a impermeabilidade das bacias hidrográficas (Kazi et al., 2009). Fatores que contribuem para isso são as ações antrópicas, dentre as quais se destaca o poder de produção, que, como consequência, aumenta os níveis de poluição, contaminação e desmatamento de fontes naturais como elemento marcante relacionado ao Brasil.

Outro fator muito importante diz respeito às condições de sustentabilidade da água pelas cidades Brasileiras, nas quais muitas têm pouca ou nenhuma preocupação com os impactos causados aos corpos hídricos devido ao crescimento populacional, rápida industrialização, além da descarga de esgoto doméstico, o que causa transtornos ao meio ambiente. (Andrietti et al., 2017).

A escassez de água é um assunto amplamente discutido (Lima et al., 2011), pois, se a água continuar a ser utilizada de maneira inadequada e sem a devida consciência da sua futura indisponibilidade, se tornará mais frequente uma água de baixa qualidade (Vidic et al., 2013), para seus usos específicos que relacionados diretamente ao homem, abrange a sua utilização para consumo humano e além deste para uso recreativo, de forma que este venha a ser utilizado atendendo aos parâmetros de 
balneabilidade, que pode ser definida como a qualidade das águas destinadas ao uso recreativo de contato primário, que é aquele destinado a atividades que envolvem o contato direto com as águas do corpo hídrico com a possibilidade de ingestão considerável de água como exemplo tem-se o mergulho (De Medeiros Martins et al., 2017) .

Devido a capacidade da água de transmitir doenças, o desconhecimento da qualidade da mesma oferece risco a quem consome ou faz uso recreativo do mesmo para o banho (Fonseca et al., 2011). A probabilidade de um banhista contrair uma doença banhando-se em águas contaminadas aumenta quando mais organismos patológicos presentes e o tempo de exposição a eles, dependendo também do grau de imunidade do indivíduo (Barna \& Kádár, 2012). Os padrões que a água necessita para estar apta para consumo como ausência de Escherichia coli ou coliformes fecais termotolerantes, em $100 \mathrm{~mL}$, ausência de coliformes totais, em $100 \mathrm{~mL}$ isso em poços nascentes, rios e lagos (Siqueira et al., 2010). Já em águas tratadas essa ausência deve estar em 95\% das amostras (Brasil, 2005).

A Portaria nº 888/2021 do Ministério da Saúde dispõe sobre os procedimentos de controle e de vigilância da qualidade da água para consumo humano e seu padrão de potabilidade. Assim, de acordo com esta portaria água potável é aquela que se enquadra aos padrões de potabilidade estabelecidos por lei, não possibilitando em riscos à saúde (da Silva Junior et al., 2021). Diante disso, uma água é considerada potável quando está dentro dos padrões segundo os parâmetros organolépticos, microbiológicos e físico-químicos (Brasil, 2021).

O enquadramento também é referência para o Sistema Nacional de meio Ambiente, pois estabelece os padrões de qualidade das águas para o monitoramento e licenciamento ambiental (Brasil, 2007). No ano de 2000 foi criada a agência nacional de águas (ANA), e em 2005, a resolução CONAMA nº 357 (Zoby, 2008; Brasil, 2013). Essa resolução define e classifica as águas em doce, salinas e salobras em função dos seus usos, seu sistema de classes e qualidade. O enquadramento dos corpos de água representa a aplicação de metas de qualidade da água a serem mantidas ou alcançadas, em determinado segmento de corpo de água, de acordo com os usos como estabelecido pelo CONAMA nº 357/2005 (Ana, 2017; Brasil, 2013).

Atualização de parâmetros físico-químicos e microbiológicos é indispensável no processo de monitoramento da qualidade da água, pois esses processos podem gerar indicadores para tratamento e melhoria a aparência da água, removendo os sólidos em fase de suspenções e favorecendo a desinfecção da água eliminando possíveis agentes patogênicos (Brito et al., 2019). O estudo do pH da água para saber se está acida ou básica (Oliveira et al. 2018) é muito importante no setor de distribuição, principalmente no abastecimento de água, pois está relacionada à coagulação/floculação da água e controle da desinfecção. Assim, a portaria no 888/2021 do Ministério da Saúde estabelece que água esteja com o pH na faixa 6,0 a 9,0 no sistema de distribuição (Brasil, 2021; da Silva Junior et al., 2021).

A detecção e quantificação de todos os microrganismos patogênicos potencialmente presentes na água não ocorre de forma simplória, possui custos são elevados e demanda muito tempo. Nem sempre são obtidos resultados positivos ou que confirmem a presença destes microrganismos. A meta da análise microbiológica da água é fornecer subsídio a respeito da sua qualidade e potabilidade, isto é, ausência de risco de ingestão de microrganismos patogênicos, geralmente oriundos da contaminação pelas fezes humanas e outros animais (FUNASA, 2013).

É válido salientar, que os microrganismos presentes em águas naturais são inofensivos à saúde humana em sua maioria. Porém, quando estes corpos de água são contaminados por esgoto sanitário, poderão apresentar microrganismos prejudiciais à saúde humana. Os microrganismos patogênicos incluem vírus, bactérias, protozoários e helmintos (FUNASA, 2013).

A balneabilidade no Brasil, ou seja, a avaliação das águas recreativas de contato primário em águas doces, salinas e salobras, deve contemplar aos padrões estabelecidos pela Resolução CONAMA no 274, de 29 de novembro de 2000. As condições de balneabilidade em águas doces são avaliadas em duas categorias própria e imprópria para o uso conforme esta resolução. As consideradas próprias são subdivididas em excelentes, muito boas e satisfatórias, definidas conforme os teores de 
coliformes fecais (termotolerantes) ou Escherichia coli (da Silva Alves, 2020).

A água para recreação é classificada baseado no tipo de contato entre o usuário e as águas (De Azevedo Lopes \& De Oliveira, 2017). O contato primário refere-se a atividades como a natação, surfe, esqui-aquático e mergulho, nos quais há possibilidade de ingestão de água (De Azevedo Lopes et al., 2013). Já o contato secundário estar associa a atividades de pesca e navegação, em que a possibilidade de ingestão de água é baixa (Lopes et al., 2019). O contato primário, ou direto, impõe condições mais restritivas à qualidade da água, devido ao risco oferecido à saúde humana pela exposição direta e prolongada a organismos patogênicos, metais pesados e óleos e graxas (Röhnelt et al., 2020).

$\mathrm{O}$ presente estudo foi realizado com a finalidade o enquadrar as classes da água dos balneários que são abastecidos pelo Córrego Mosquito, através de análises físico-química e microbiológica, verificar se esta água atende aos parâmetros estabelecidos pela Portaria No 888/2021 do Ministério da Saúde (Brasil, 2021), identificar se a água de cada balneário está própria ou imprópria de acordo com a Resolução CONAMA n 274 , de 29 de novembro de 2000 e para os usos segundo a Resolução CONAMA n 357, de 17 de março de 2005 (Campos \& Azevedo, 2013; Brasil, 2013).

\section{Metodologia}

\subsection{Tipo e local do estudo}

O presente estudo enquadra-se como exploratório descritivo com método experimental através de coleta sistemática de dados, registro, análise, e interpretação dos fenômenos observados (Dos Santos et al., 2020; Pereira et al., 2018) e foi realizado em quatro balneários localizados no município de Açailândia - MA.

A observação inicial da área de estudo foi feita através da análise de imagens de satélite, utilizando georreferenciamento pela ferramenta exploratória Google Earth (Guimaraes et al., 2012) e visita in situ. 
Figura 1. Imagem de satélite dos pontos amostrais.

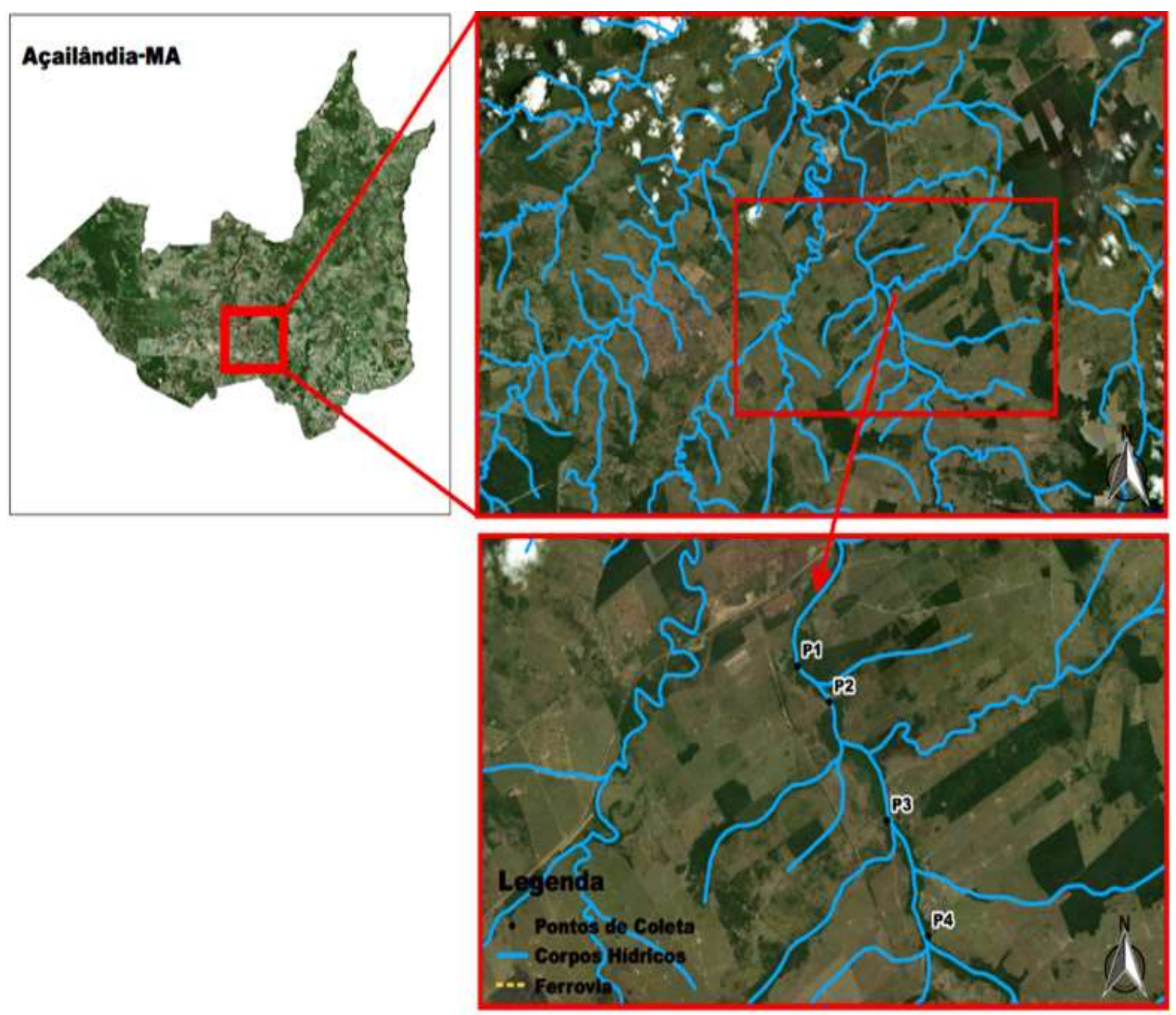

Fonte: Google Earth (2021).

A Figura 1 mostra a área geográfica do município de Açailândia e na parte ampliada mostra os pontos de coleta das amostras e os respectivos trajetos dos corpos hídricos onde o córrego Mosquito está inserido. Este córrego está localizado a 11 km da UEMASUL - Universidade Estadual da Região Tocantina do Maranhão (Campus Açailândia) e a 74 km de distância do município de Imperatriz -MA.

Tabela 1. Coordenadas geográficas dos pontos amostrais.

\begin{tabular}{c|c|c}
\hline PONTOS & LATITUDE & LONGITUDE \\
\hline Ponto 1: Águas rasas & -4.9632254 & -47.3663383 \\
\hline Ponto 2: Pantanal & -4.9446036 & -47.3743876 \\
\hline Ponto 3: Valter Figueiredo & -4.9254849 & -47.3856536 \\
\hline Ponto 4: Vale dos peixes & -4.9197231 & -47.3918428 \\
\hline
\end{tabular}

Fonte: Autores (2021).

A Tabela 1 mostra as coordenadas geográficas dos balneários: Águas Rasas, Pantanal, Valter Figueiredo e Vale dos Peixes e estes foram nomeados como pontos 1, 2, 3 e 4 respectivamente. O critério de escolha dos pontos de coleta das amostras se deu pelo fato de serem os mais frequentados pela população para utilização de água recreativa na cidade de Açailândia. 


\subsection{Coleta das amostras}

As amostras de água foram coletadas e preservadas de acordo com a NBR ISO/ IEC 17.025 (Jardim \& Sodre, 2009) e o Manual Prático de Análise de Água (FUNASA, 2013) em quatro balneários: Águas Rasas, Pantanal, Valter Figueiredo e Vale dos Peixes todos abastecidos pelo córrego Mosquito que tem sua nascente localizada entre o povoado do Trecho Seco e a cidade de São Francisco do Brejão e desaguando no rio Açailândia em maio de 2020 em dias com ausência de precipitação pluviométrica.

\subsection{Análises físico-química e microbiológica}

Após a coleta das amostras, estas foram enviadas para o Laboratório de Biotecnologia Ambiental (LABITEC) da Universidade Estadual da Região Tocantina do Maranhão (UEMASUL) Campus Imperatriz onde foram utilizadas as metodologias APHA, EPA, SM, e FUNASA, para a obtenção dos resultados (APHA, 2017; Ferrer et al., 2010; Griffith et al., 2006; Santos, 2010; Rice, Baird, Eaton., \& Clesceri, 2012; Brasil, 2014; FUNASA, 2013).

Os parâmetros físico-químicos analisados foram turbidez, $\mathrm{pH}$, concentrações de cloreto, ferro solúvel, fósforo total, sólidos totais dissolvidos, óleos e graxas, sulfatos nitrato, nitrito e nitrogênio amoniacal (Decker et al., 2018; Brasil 2021). A classificação da qualidade da água em parâmetros microbiológicos foi feita como própria e imprópria. A classificada como própria foi dividida em três categorias: excelente, muito boa e satisfatória (Morais \& Silva, 2012).

As amostras analisadas foram separadas P1, P2, P3 e P4 de acordo com os locais de coleta, Águas Rasas (P1), Pantanal (P2), Valter Figueiredo (P3) e Vale dos Peixes (P4) respectivamente. Cada ponto teve três amostras analisadas e estas foram nomeadas em PnA, PnB e PnC onde n é relativo ao ponto (1, 2, 3 e 4) e depois de obtidos os resultados foi feita a média aritmética dos três valores e obtido valor de cada parâmetro analisado e comparando-os com os tipos de classes existentes e em seguida foi feita classificação da qualidade da água de acordo com a presença coliformes fecais termotolerantes.

\subsection{Enquadramento do corpo de água}

O enquadramento dos corpos de água representa a aplicação de metas de qualidade da água a serem mantidas ou alcançadas, em determinado segmento de corpo de água, de acordo com os usos como estabelecido pelo CONAMA $\mathrm{n}^{\circ}$ 357/2005 (Brasil, 2013). Para realizar o enquadramento, após os resultados das análises laboratoriais das amostras, utilizou-se o Quadro 1, parâmetros de qualidade da água para balneabilidade de acordo com a Resolução CONAMA no 274, de 29 de novembro de 2000 classificando como própria ou impropria, para averiguar em qual classe a água de cada ponto coletado poderia ser classificado.

De acordo com a Resolução CONAMA n 274/2000, os critérios de balneabilidade em águas brasileiras, as águas destinadas à recreação de contato primário terão suas condições avaliadas nas categorias imprópria e própria, sendo que as caracterizadas como próprias, são subdivididas em excelente, muito boa e satisfatória, de acordo com a quantidade de coliformes fecais (termotolerantes) ou Escherichia coli encontrados em um conjunto de amostras de um determinado local.

Contagens de microrganismos pelo Número Mais Provável (NMP) é uma técnica que permitem avaliar e quantidade de microrganismos presentes em uma amostra e estimar a proporção viável metabolicamente ativa. A determinação do NMP de coliformes em uma amostra é efetuada aplicando a técnica de tubos múltiplos. Este método parte do pressuposto de que as bactérias presentes na amostra podem ser dissociadas por agitação, resultando assim, em uma suspensão distribuída uniformemente de células (Ribeiro, Barros \& Barros, 2021). 
Quadro 1. Classificação da qualidade água e os respectivos limites de concentração de microrganismos.

\begin{tabular}{|l|l|c|c|}
\hline Classificação & Categoria & $\begin{array}{c}\text { Coliformes fecais / termotolerantes } \\
(\mathbf{N M P} / \mathbf{1 0 0} \mathbf{~ m L})\end{array}$ & $\begin{array}{c}\text { Escherichia coli } \\
(\mathbf{N M P} / \mathbf{1 0 0} \mathbf{~ m L})\end{array}$ \\
\hline \multirow{3}{*}{ Própria } & Excelente & 250 & 200 \\
\cline { 2 - 4 } & Muito Boa & 500 & 400 \\
\cline { 2 - 4 } & Satisfatória & 1.000 & 800 \\
\hline Imprópria & Acima de 1.000 & Acima de 800 \\
\hline
\end{tabular}

Fonte: Morais e Silva (2012), adaptado pelos autores.

O Quadro 1 acima traz a classificação da água como própria e suas subdivisões em excelente, muito boa e satisfatória, além de impropria de acordo com a concentração de microrganismos pelo método do número mais provável (NMP) por 100 mL de solução (Bettega et al., 2006; Morais \& Silva, 2012). Logo em seguida, utilizou-se a Figura 4 para averiguar para quais fins esta água pode estar sendo destinada de acordo com Resolução CONAMA no 357/2005 (Brasil, 2013).

Figura 2. Classes de qualidade da água e relação com os usos.

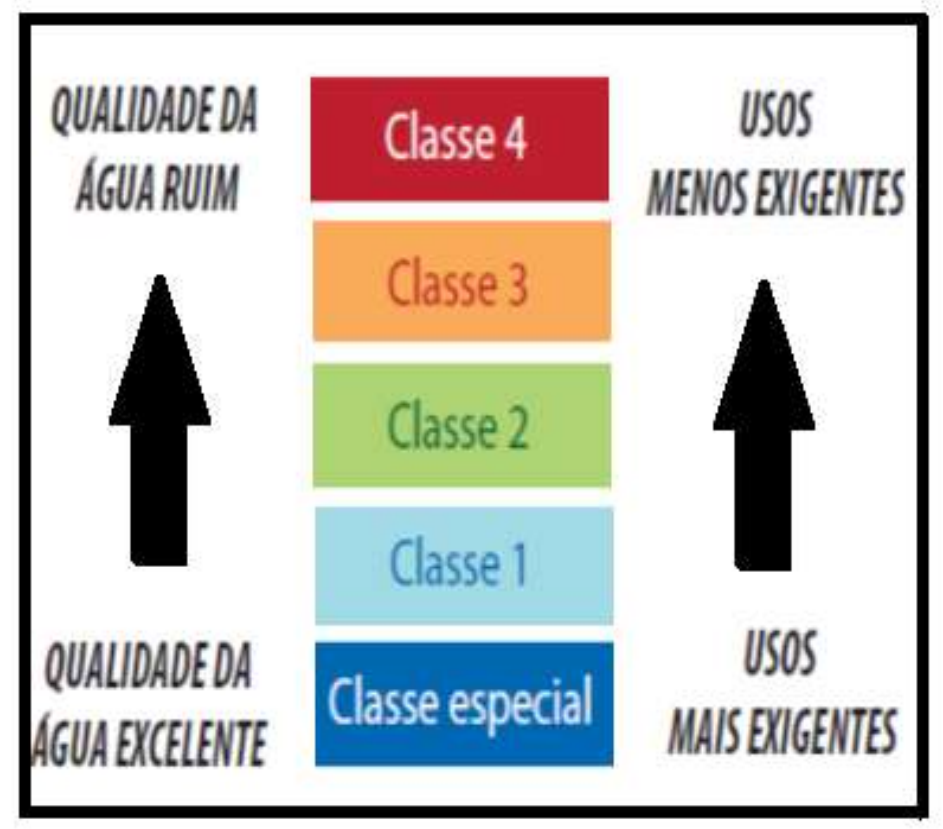

Fonte: Resolução CONAMA n³57/2005, adaptada pelos autores.

A Figura 2 mostra as quatro classes de qualidade da água, onde a que possui qualidade excelente é chamada de classe especial e a de qualidade ruim classe 4. Em relação aos usos que podem ser mais exigentes ou menos exigentes, também relacionadas as classes (Brasil, 2013).

O objetivo do enquadramento é assegurar a qualidade compatível com cada uso que as águas forem destinadas, como também diminuir os custos de combate à poluição das águas, mediante ações preventivas permanentes. Para isso, foram criadas classes da qualidade de água considerando usos mais ou menos exigentes (Souza et al., 2014). Para as águas doces, foram criadas cinco categorias, a classe especial e as classes de 1 a 4, em uma ordem decrescente de qualidade, ou seja, a classe especial é a que tem melhor qualidade da água e a classe 4 é a de pior qualidade (Dos Santos et al., 2014). 


\section{Resultados e Discussão}

Nesta seção mostram-se os resultados das análises físico-química e microbiológica e para a realização do enquadramento foram utilizadas as informações presentes no Quadro 1 que lista os principais parâmetros a serem observados nos resultados das análises de laboratório.

\subsection{Resultados da análise físico-química}

As Tabelas 2, 3, 4 e 5 mostram as médias dos resultados dos parâmetros necessários para o enquadramento dos pontos 1, 2, 3 e 4 respectivamente e comparando-os com os parâmetros de classes estabelecidos pela Resolução CONAMA ${ }^{\circ}$ 357/2005 e Portaria no 888/2021 Ministério da Saúde (MS) (Brasil, 2013; Brasil, 2021). As lacunas destacadas com a cor verde mostram a possibilidade de enquadramento dentro classe de acordo resultado médio das amostras.

Tabela 2. Resultados do ponto 1 em comparação aos parâmetros de enquadramento.

\begin{tabular}{|c|c|c|c|c|c|c|c|}
\hline \multirow{2}{*}{ Parâmetro } & \multirow{2}{*}{$\begin{array}{c}\text { Média } \\
\text { dos } \\
\text { P.1(ABC) }\end{array}$} & \multirow{2}{*}{ Unidades } & \multicolumn{5}{|c|}{ Classes } \\
\hline & & & Especial & 1 & 2 & 3 & 4 \\
\hline Turbidez & 4,60 & UT & \multirow{11}{*}{$\begin{array}{c}\text { Mantidas As } \\
\text { Condições } \\
\text { Naturais Do } \\
\text { Corpo de } \\
\text { Água }\end{array}$} & $\leq 40$ & $\leq 100$ & $\leq 100$ & - \\
\hline $\mathrm{pH}$ & 5,52 & - & & 6 a 9 & 6 a 9 & 6 a 9 & 6 a 9 \\
\hline Cloreto & $<0,001$ & $\mathrm{mg} / \mathrm{L}$ & & $\leq 250$ & $\leq 250$ & $\leq 250$ & - \\
\hline $\begin{array}{l}\text { Ferro } \\
\text { solúvel } \\
\end{array}$ & 0,92 & $\mathrm{mg} / \mathrm{L}$ & & $\leq 0,3$ & $\leq 0,3$ & $\leq 0,5$ & - \\
\hline $\begin{array}{l}\text { Fósforo } \\
\text { total }\end{array}$ & 35,20 & $\mathrm{mg} / \mathrm{L}$ & & 0,020 & 0,030 & 0,05 & - \\
\hline $\begin{array}{l}\text { Sólidos } \\
\text { totais } \\
\text { dissolvidos }\end{array}$ & 0,93 & $\mathrm{mg} / \mathrm{L}$ & & $\leq 500$ & $\leq 500$ & $\leq 500$ & - \\
\hline $\begin{array}{l}\text { Óleos e } \\
\text { graxas }\end{array}$ & Ausência & $\mathrm{mg} / \mathrm{L}$ & & Ausência & Ausência & Ausência & Permitida \\
\hline Sulfato & 20.78 & $\mathrm{mg} / \mathrm{L}$ & & $\leq 250$ & $\leq 250$ & $\leq 250$ & - \\
\hline Nitrato & 11,51 & $\mathrm{mg} / \mathrm{L}$ & & $\leq 10$ & $\leq 10$ & $\leq 10$ & - \\
\hline Nitrito & 3,16 & $\mathrm{mg} / \mathrm{L}$ & & $\leq 1$ & $\leq 1$ & $\leq 1$ & - \\
\hline $\begin{array}{l}\text { Nitrogênio } \\
\text { Amoniacal }\end{array}$ & 5,74 & $\mathrm{mg} / \mathrm{L}, \mathrm{pH}<7.5$ & & 3,7 & 3,7 & 13,3 & - \\
\hline
\end{tabular}

Fonte: Autores (2021).

Na Tabela 2 são mostrados os resultados do ponto 1 onde o potencial hidrogeniônico (pH) médio foi 5,52 e turbidez de 4,60 UT. O pH é um parâmetro considerado para a balneabilidade das águas pois pode ser um indicador de poluição do corpo hídrico e este valor de pH está abaixo do intervalo de 6 a 9 não estando em conformidade com a Portaria de n. ${ }^{\circ} 888$ de 4 de maio de 2021 do MS (Marques, 2020; da Silva Junior, 2021). Houve também, ausência de óleos e graxas em todas as amostras analisadas. Os cloretos apresentaram concentrações menores que $0,001 \mathrm{mg} / \mathrm{L}$. O ferro solúvel teve concentração 0,92 $\mathrm{mg} / \mathrm{L}$ e fósforo total 35,20 mg/L. Assim, observou-se que a parâmetros analisados em sua maioria, não se encontram em conformidade com a Portaria 888/2021 do MS, apresentando valores acima do permitido.

Estudar as características físico-químicas da água têm como objetivo quantificar e identificar os elementos presentes nesse composto e associar os efeitos de suas propriedades às questões ambientais. A interpretação e o conhecimento destas 
propriedades físico-químicas possibilitam responder perguntas como, quais e em que nível eles podem ser impróprios a saúde humana e aos ecossistemas (Parreira \& Oliveira, 2017).

De acordo com os resultados apresentados da Tabela 2, possivelmente o enquadramento adequado para o corpo hídrico no ponto 1 é da classe 3 para e pode ser destinado ao abastecimento para consumo humano após tratamento convencional ou avançado, à irrigação de culturas arbóreas, cerealíferas e forrageiras, à pesca amadora, à recreação de contato secundário (Brasil, 2005).

Tabela 3. Resultados do ponto 2 em comparação aos parâmetros de enquadramento.

\begin{tabular}{|c|c|c|c|c|c|c|c|}
\hline \multirow{2}{*}{ Parâmetro } & \multirow{2}{*}{$\begin{array}{l}\text { Média dos } \\
\text { P.2(ABC) }\end{array}$} & \multirow{2}{*}{ Unidades } & \multicolumn{5}{|c|}{ Classes } \\
\hline & & & Especial & 1 & 2 & 3 & 4 \\
\hline Turbidez & 3,96 & UT & \multirow{11}{*}{$\begin{array}{c}\text { Mantidas } \\
\text { As } \\
\text { Condições } \\
\text { Naturais } \\
\text { Do Corpo } \\
\text { De Água }\end{array}$} & $\leq 40$ & $\leq 100$ & $\leq 100$ & - \\
\hline $\mathrm{pH}$ & 5,33 & - & & 6 a 9 & 6 a 9 & 6 a 9 & 6 a 9 \\
\hline Cloreto & 0,001 & $\mathrm{mg} / \mathrm{L}$ & & $\leq 250$ & $\leq 250$ & $\leq 250$ & - \\
\hline $\begin{array}{l}\text { Ferro } \\
\text { solúvel }\end{array}$ & 0,76 & $\mathrm{mg} / \mathrm{L}$ & & $\leq 0,3$ & $\leq 0,3$ & $\leq 0,5$ & - \\
\hline Fosforo total & 17,68 & $\mathrm{mg} / \mathrm{L}$ & & 0,020 & 0,030 & 0,05 & - \\
\hline $\begin{array}{l}\text { Sólidos } \\
\text { totais } \\
\text { dissolvidos }\end{array}$ & 1,43 & $\mathrm{mg} / \mathrm{L}$ & & $\leq 500$ & $\leq 500$ & $\leq 500$ & - \\
\hline $\begin{array}{l}\text { Óleos e } \\
\text { graxas }\end{array}$ & Ausência & $\mathrm{mg} / \mathrm{L}$ & & Ausência & Ausência & Ausência & Permitida \\
\hline Sulfatos & 39,88 & $\mathrm{mg} / \mathrm{L}$ & & $\leq 250$ & $\leq 250$ & $\leq 250$ & - \\
\hline Nitrato & 7,45 & $\mathrm{mg} / \mathrm{L}$ & & $\leq 10$ & $\leq 10$ & $\leq 10$ & - \\
\hline Nitrito & 0,94 & $\mathrm{mg} / \mathrm{L}$ & & $\leq 1$ & $\leq 1$ & $\leq 1$ & - \\
\hline $\begin{array}{l}\text { Nitrogênio } \\
\text { Amoniacal }\end{array}$ & 1,74 & $\mathrm{mg} / \mathrm{L}, \mathrm{pH}<7.5$ & & 3,7 & 3,7 & 13,3 & - \\
\hline
\end{tabular}

Fonte: Autores (2021).

É mostrada a Tabela 3 com resultados do ponto 2 em comparação aos parâmetros de enquadramento. A turbidez média foi de 3,96 UT, o potencial hidrogeniônico (pH) médio foi 5,33 valores abaixo do intervalo de 6 a 9. Houve ausência de óleos e graxas em todas as amostras.

Ao realizar uma análise de água, devem-se selecionar os parâmetros a serem investigados pela análise, pois variam de acordo com a finalidade dela. Os parâmetros avaliados e suas principais características físicas e químicas da água, as quais em seu conjunto permitem a avaliação da qualidade da água destinada ao consumo ou outros usos (Neto et al., 2017).

A maioria dos parâmetros analisados no ponto 3 encontram-se em conformidade com a Portaria de $n^{\circ}$ 888/2021 do MS, apresentando apenas alguns valores acima do permitido (Brasil, 2021). Assim, baseado na Tabela 3 possivelmente o enquadramento para o corpo hídrico no ponto 2 é da classe 2 e pode ser destinado ao abastecimento para consumo humano após tratamento convencional, à proteção das comunidades aquáticas, à recreação de contato primário, tais como natação, esqui aquático e mergulho, à irrigação de hortaliças, plantas frutíferas e de parques, jardins, campos de esporte e lazer, com os quais o público possa vir a ter contato direto e à aquicultura e à atividade de pesca (Brasil, 2005). 
Tabela 4. Resultados do ponto 3 em comparação aos parâmetros de enquadramento.

\begin{tabular}{|c|c|c|c|c|c|c|c|}
\hline \multirow{2}{*}{ Parâmetro } & \multirow{2}{*}{$\begin{array}{l}\text { Média dos } \\
\text { P.3(ABC) }\end{array}$} & \multirow{2}{*}{ Unidades } & \multicolumn{5}{|c|}{ Classes } \\
\hline & & & Especial & 1 & 2 & 3 & 4 \\
\hline Turbidez & 4,2 & UT & \multirow{11}{*}{$\begin{array}{c}\text { Mantidas } \\
\text { As } \\
\text { Condições } \\
\text { Naturais } \\
\text { Do Corpo } \\
\text { De Água }\end{array}$} & $\leq 40$ & $\leq 100$ & $\leq 100$ & - \\
\hline $\mathrm{pH}$ & 5,53 & - & & 6 a 9 & 6 a 9 & 6 a 9 & 6 a 9 \\
\hline Cloreto & 0,001 & $\mathrm{mg} / \mathrm{L}$ & & $\leq 250$ & $\leq 250$ & $\leq 250$ & - \\
\hline $\begin{array}{l}\text { Ferro } \\
\text { solúvel }\end{array}$ & 1,25 & $\mathrm{mg} / \mathrm{L}$ & & $\leq 0,3$ & $\leq 0,3$ & $\leq 0,5$ & - \\
\hline Fósforo total & 48,95 & $\mathrm{mg} / \mathrm{L}$ & & 0,020 & 0,030 & 0,05 & - \\
\hline $\begin{array}{l}\text { Sólidos } \\
\text { totais } \\
\text { dissolvidos }\end{array}$ & 1,76 & $\mathrm{mg} / \mathrm{L}$ & & $\leq 500$ & $\leq 500$ & $\leq 500$ & - \\
\hline $\begin{array}{l}\text { Óleos e } \\
\text { graxas }\end{array}$ & Ausência & $\mathrm{mg} / \mathrm{L}$ & & Ausência & Ausência & Ausência & Permitida \\
\hline Sulfatos & 69,78 & $\mathrm{mg} / \mathrm{L}$ & & $\leq 250$ & $\leq 250$ & $\leq 250$ & - \\
\hline Nitrato & 12,09 & $\mathrm{mg} / \mathrm{L}$ & & $\leq 10$ & $\leq 10$ & $\leq 10$ & - \\
\hline Nitrito & 1,54 & $\mathrm{mg} / \mathrm{L}$ & & $\leq 1$ & $\leq 1$ & $\leq 1$ & - \\
\hline $\begin{array}{l}\text { Nitrogênio } \\
\text { Amoniacal }\end{array}$ & 2,11 & $\mathrm{mg} / \mathrm{L}, \mathrm{pH}<7.5$ & & 3,7 & 3,7 & 13,3 & - \\
\hline
\end{tabular}

Fonte: Autores (2021).

Os resultados do ponto 3 são exibidos na Tabela 4 onde a turbidez média foi de 3,96 UT, o potencial hidrogeniônico (pH) médio foi 5,33 valores abaixo do intervalo de 6 a 9. Houve ausência de óleos e graxas em todas as amostras. A água pode sofrer contaminações que estão relacionadas às alterações nas características químicas, físicas e/ ou biológicas, causando prejuízo à saúde da população, e comprometendo a fauna e a utilização das águas para fins comerciais, industriais, recreativos e de geração de energia, assim, esses tipos de contaminantes devem ser monitorados frequentemente para que não possam causar prejuízos a saúde pública (de Oliveira et al., 2018).

Baseando-se na Portaria no 888/2021 do Ministério da Saúde (MS), os parâmetros analisados não se encontram em conformidade com os valores permitidos, apresentando valores superiores em sua maioria. Possivelmente o enquadramento mais adequado para o corpo hídrico no ponto 3 é da classe 3, podendo ser destinado ao abastecimento para consumo humano após tratamento convencional ou avançado, à irrigação de culturas arbóreas, cerealíferas e forrageiras, à pesca amadora, à recreação de contato secundário (Brasil, 2005). 
Tabela 5. Resultados do ponto 4 em comparação aos parâmetros de enquadramento.

\begin{tabular}{|c|c|c|c|c|c|c|c|}
\hline \multirow{2}{*}{ Parâmetro } & \multirow{2}{*}{$\begin{array}{l}\text { Média dos } \\
\text { P.4(ABC) }\end{array}$} & \multirow{2}{*}{ Unidades } & \multicolumn{5}{|c|}{ Classes } \\
\hline & & & Especial & 1 & 2 & 3 & 4 \\
\hline Turbidez & 6,59 & UT & \multirow{11}{*}{$\begin{array}{c}\text { Mantidas } \\
\text { As } \\
\text { Condições } \\
\text { Naturais } \\
\text { Do Corpo } \\
\text { De Água }\end{array}$} & $\leq 40$ & $\leq 100$ & $\leq 100$ & - \\
\hline $\mathrm{pH}$ & 5,67 & - & & 6 a 9 & 6 a 9 & 6 a 9 & 6 a 9 \\
\hline Cloreto & 0,001 & $\mathrm{mg} / \mathrm{L}$ & & $\leq 250$ & $\leq 250$ & $\leq 250$ & - \\
\hline Ferro solúvel & 2,51 & $\mathrm{mg} / \mathrm{L}$ & & $\leq 0,3$ & $\leq 0,3$ & $\leq 0,5$ & - \\
\hline Fosforo total & 88,79 & $\mathrm{mg} / \mathrm{L}$ & & 0,020 & 0,030 & 0,05 & - \\
\hline $\begin{array}{l}\text { Sólidos totais } \\
\text { dissolvidos }\end{array}$ & 3,37 & $\mathrm{mg} / \mathrm{L}$ & & $\leq 500$ & $\leq 500$ & $\leq 500$ & - \\
\hline $\begin{array}{l}\text { Óleos e } \\
\text { graxas }\end{array}$ & Presença & $\mathrm{mg} / \mathrm{L}$ & & Ausência & Ausência & Ausência & Presença \\
\hline Sulfatos & 100,79 & $\mathrm{mg} / \mathrm{L}$ & & $\leq 250$ & $\leq 250$ & $\leq 250$ & - \\
\hline Nitrato & 19,23 & $\mathrm{mg} / \mathrm{L}$ & & $\leq 10$ & $\leq 10$ & $\leq 10$ & - \\
\hline Nitrito & 2,39 & $\mathrm{mg} / \mathrm{L}$ & & $\leq 1$ & $\leq 1$ & $\leq 1$ & - \\
\hline $\begin{array}{l}\text { Nitrogênio } \\
\text { Amoniacal } \\
\end{array}$ & 3,98 & $\mathrm{mg} / \mathrm{L}, \mathrm{pH}<7.5$ & & 3,7 & 3,7 & 13,3 & - \\
\hline
\end{tabular}

Fonte: Autores (2021).

Conforme os resultados exibidos na Tabela 5, o ponto 4 foi único que teve presença de óleos e graxas seu pH foi de 5,67, sua turbidez 6,59 UT e pode ser classificado possivelmente como água de classe 3, pois a maioria dos parâmetros tendem para esse nível. De acordo com a Agência Nacional de Águas (Zoby, 2008) águas do tipo 3 podem ser utilizadas para consumo humano após tratamento convencional com clarificação, com a utilização de coagulação e floculação, seguida de desinfecção e correção de pH, ou tratamento avançado técnicas de remoção e/ou inativação de constituintes refratários aos processos convencionais de tratamento, os quais podem conferir à água características, tais como: cor, odor, sabor, atividade tóxica ou patogênica (Brasil, 2005).

A maioria dos parâmetros do ponto 4 não se encontram conformidade com a Portaria de $n^{\circ}$ 888/2021 do MS, apresentando valores acima do permitido (Brasil, 2021). A água do balneário relativo ao ponto 4 pode ser utilizada para recreação de contato secundário refere-se àquela associada a atividades em que o contato com a água é esporádico ou acidental e a possibilidade de ingerir água é pequena, como na pesca e na navegação (tais como iatismo). A pesca e irrigação de culturas arbóreas cerealíferas e forrageiras são outros usos, além da dessedentação de animais navegação e harmonia paisagística (Brasil, 2005).

O uso de águas para atividades de recreação de contato primário exige requisitos mais restritivos de qualidade, que devem atender às condições de balneabilidade, considerando o risco oferecido à saúde em corpos hídricos contaminados pela exposição direta e prolongada a organismos patogênicos, óleos e graxas, toxinas, metais pesados, presentes em corpos hídricos contaminados dentre outros (Oliveira \& Buss, 2018). O quadro de poluição da água pode ser monitorado através dos resultados de análise físico-química, assim, para ter o conhecimento da qualidade da água e se ela passou pelo tratamento adequado, tornando-a livre dessas poluições iniciais faz-se necessário esse tipo de análise. Porém, para que se obtenha uma maior confiança dessa qualidade, deve-se realizar, além de análises físico-químicas, análises microbiológicas, cujos resultados são expressos em qualidade e quantidade de organismos presentes (Oliveira \& Buss, 2018). 


\subsection{Resultados da análise microbiológica}

Uma água de boa qualidade ideal deve apresentar ausência de coliformes fecais termotolerantes ou possuir concentrações NMP/100 mL, condições estas aceitáveis para ser classificada como própria (Fernandes \& Gois, 2015). Assim, com o intuito de avaliar a adequação das amostras presentes no estudo em relação este parâmetro microbiológico, foi elaborada a Tabela 6 com resultados dos 4 pontos de coleta em comparação ao padrão adequado como preconiza a Resolução CONAMA $n^{\circ} 274 / 2000$ sobre a balneabilidade.

Tabela 6. Classificação da qualidade da água de acordo com coliformes fecais termotolerantes.

\begin{tabular}{c|c|c|c|c|c}
\hline \multicolumn{2}{c|}{ Categoria } & $\begin{array}{c}\text { Padrão aceito } \\
\text { (NMP/100 mL) }\end{array}$ & $\begin{array}{c}\text { Pontos de } \\
\text { coleta }\end{array}$ & $\begin{array}{c}\text { Quantidade de } \\
\text { Coliformes fecais/ } \\
\text { termotolerantes } \\
\text { (NMP/100 mL) }\end{array}$ & Categoria \\
\hline \multirow{3}{*}{ Própria } & Excelente & 250 & P1 & $\geq 1.600$ & Imprópria \\
\cline { 2 - 6 } & Muito Boa & 500 & P2 & $\geq 1.600$ & Imprópria \\
\cline { 2 - 6 } & Satisfatória & 1000 & P3 & $\geq 1.600$ & Imprópria \\
\hline \multicolumn{2}{l}{ Imprópria } & $>1000$ & P4 & $\geq 1.600$ & Imprópria \\
\hline
\end{tabular}

Fonte: Autores (2021).

A Tabela 6 mostra que em todos os pontos de coleta (P1, P2, P3 e P4) a quantidade de coliformes fecais termotolerantes está acima do permitido com concentrações acima $1.600 \mathrm{NMP} / 100 \mathrm{~mL}$ e a partir destes resultados, os balneários tiveram suas águas classificadas como impróprias para a balneabilidade. Assim, possivelmente as pessoas que têm contato de forma primária com esse corpo hídrico estão sujeitas a serem acometidas por doenças de vinculação hídrica, devido às altas concentrações destes microrganismos patogênicos presentes na água. Os resultados mostrados na tabela 7 possivelmente classificam este corpo hídrico (córrego Mosquito) como classe 3, necessitando de tratamento convencional ou avançado para assim ter a água destinado para o consumo.

As análises físico-químicas e microbiológicas são importantes pois avaliam e monitoram a qualidade da água para o uso humano, fornecendo auxílio às políticas de proteção ambiental e de saúde pública (de Oliveira et al., 2018). A destinação dessa água nos balneários é para uso recreativo, paisagístico turístico e de contato primário. De acordo com os parâmetros obtidos e o enquadramento feito neste estudo, as amostras água analisadas estão inapropriadas para estes tipos de usos.

\section{Considerações Finais}

O principal objetivo do enquadramento é assegurar a qualidade da água, e verificar se a destinações de seus usos estão adequadas, assim podendo reduzir custos em outras áreas como a da saúde. Saber antecipadamente que determinada água é apropriada para consumo ou contato primário pode evitar que a população que faz uso dela, tenha complicações relativas ao desconhecimento desta temática. Assim, a partir dos resultados obtidos, é possível afirmar que os parâmetros físico-químicos e microbiológicos dos pontos P1, P2, P3 e P4 em sua maioria não se encontraram em conformidade com a Resolução CONAMA $n^{\circ} 274 / 2000$ e com a Portaria no $888 / 2021$ do MS.

A água em todos os pontos está inapropriada para a balneabilidade apresentando uma predominância de classe 3, além de apresentar quantidade de coliformes fecais/termotolerantes em todos os pontos maiores ou iguais a $1600 \mathrm{NMP} / 100 \mathrm{~mL}$, sendo que, para ter uma qualidade de água no mínimo satisfatória deve apresentar valores de no máximo 1000 NMP/100 mL. Assim, a água em todos os pontos de coleta analisados não está apta para o contato primário.

A adequação dos corpos de água deve ser solicitada pelo órgão ambiental responsável do município ou estado, no caso de Açailândia - MA, a Secretaria Municipal de Meio Ambiente. Assim, o presente trabalho possui resultados que podem 
servir de paramentos que podem fundamentar o pedido de adequação além de mostrar-se importante para esclarecer que existe a necessidade desse enquadramento e que a qualidade da balneabilidade está sendo afetada.

Como perspectiva futura deste trabalho, pretende-se incluir mais pontos de análise de água recreativa no município de Açailândia, visando uma quantificação mais ampla e incluir outros parâmetros físico-químicos e microbiológicos a serem analisados além de investigar os possíveis motivos dos parâmetros estarem fora dos padrões da legislação.

\section{Referências}

Ana, A. N. A. (2017). Indicadores de qualidade - Índice de Qualidade das Águas. http://portalpnqa.ana.gov.br/indicadores-indice-aguas.aspx

Andrietti, G., Freire, R., Amaral, A. G. D., Almeida, F. T. D., Bongiovani, M. C., \& Schneider, R. M. (2016). Índices de qualidade da água e de estado trófico do rio Caiabi, MT. Revista Ambiente \& Água, 11, 162-175.

APHA- American Public Health Association (2017). Standard Methods for the Examinations of Water and Wastewater. American Public Associations. 23th Washington DC.

Barna, Z., \& Kádár, M. (2012). The risk of contracting infectious diseases in public swimming pools: a review. Annali dell'Istituto superiore di sanita, 48, 374-386.

Batista, P. D. S., Mancini, C. E., \& Barreto, E. S. (2015). Analysis of total and fecal coliforms on irrigation waters of vegetable gardens in Sinop-MT, Brazil. Scientific Electronic Archives, 8(1), 50-55.

Bettega, J. M. P. R., Machado, M. R., Presibella, M., Baniski, G., \& Barbosa, C. D. A. (2006). Métodos analíticos no controle microbiológico da água para consumo humano. Ciência e Agrotecnologia, 30, 950-954.

Brasil. (2005). Resolução CONAMA 357 de 17 de março de 2005. Diário Oficial da União, 18(mar), 58-63.

Brasil. Fundação Nacional de Saúde (2013). Manual prático de análise de água- manual de bolso. (4a ed.), http://www.funasa.gov.br/site/wpcontent/files_mf/eng_analAgua.pdf

Brasil. Ministério da Saúde. Fundação Nacional de Saúde (2014). Manual de controle da qualidade da água para técnicos que trabalham em ETAS. Disponível em: http://www.funasa.gov.br/biblioteca-eletronica/publicacoes/saude-ambiental/-/asset_publisher/G0cYh3ZvWCm9/content/manual-de-controleda-qualidade-da-agua-para-tecnicos-que-trabalham-em-etas?inheritRedirect=false

Brasil. (2000). Resolução CONAMA n 274 de 29 de novembro de 2000. Dispõe sobre Classificação das águas doces, salobras e salinas essencial à defesa dos níveis de qualidade, avaliados por parâmetros e indicadores específicos, de modo a assegurar as condições de balneabilidade; de forma a assegurar as condições necessárias à recreação de contato primário. Disponível em: http://www2.mma.gov.br/port/conama/legiabre.cfm?codlegi=272.

Brito, F. S. L., Norat, M. D. V. C., \& Ribeiro, E. I. S. (2019). Utilização de diferentes metodologias para avaliação do consumo e qualidade da água dos bebedouros da Universidade Federal do Pará-UFPA. Revista Gestão \& Sustentabilidade Ambiental, 8(1), $1043-1061$.

Campos, M. M., \& Azevedo, F. R. (2013). Aproveitamento de águas pluviais para consumo humano direto. Jornal Eletrônico Faculdade Vianna Júnior, 5(1), 20-20.

Capellari, A., \& Capellari, M. B. (2018). A água como bem jurídico, econômico e social. A necessidade de proteção das nascentes. Cidades. Comunidades e Territórios, (36).

da Silva Alves, L., Machado, B. B. N., \& de Oliveira, D. F. (2020). Balneabilidade das praias do litoral de Salvador-BA: investigação da interferência da precipitação nas densidades de Escherichia coli. Revista Brasileira de Meio Ambiente, 8(4).

da Silva Junior, A. B., Gama, M. F. S., Figueiredo, L. A. P., \& Vergara, C. M. A. C. (2021). Análises físico-químicas e microbiológicas de água de poços utilizada na produção alimentícia em um complexo turístico do Estado do Ceará. Research, Society and Development, 10(10), e271101018839e271101018839.

de Azevedo Lopes, F. W., \& de Oliveira, C. K. R. (2017). Protocolo para avaliação da qualidade sanitária e ambiental em balneários de águas doces no Brasil. Hygeia-Revista Brasileira de Geografia Médica e da Saúde, 13(25), 1-17.

de Azevedo Lopes, F. W., Magalhães Jr, A. P., \& Von Sperling, E. (2013). Balneabilidade em águas doces no Brasil: riscos a saúde, limitações metodológicas e operacionais. Hygeia-Revista Brasileira de Geografia Médica e da Saúde, 9(16), 28-47.

de Medeiros Martins, L. M., de Araújo Medeiros, L. R., Rosas, R. D. A. R., \& Reis, A. L. Q. (2017). Análise dos parâmetros de balneabilidade: um estudo de caso sobre as praias dos municípios de João Pessoa e Cabedelo/PB. Revista InterScientia, 5(1), 116-128.

de Oliveira, E. M., Ribeiro, D. M., de Oliveira Cronemberger, M. G., de Carvalho, W. F., Lima, M. D. P., \& Sousa, K. R. F. (2018). Análises físico-químicas e microbiológicas da água de bebedouros em escolas públicas da cidade de Timon-MA. PUBVET, 12, 172.

Decker, A., Pacheco, M., Quadro, M., Soares, H., Nadaletti, W., \& Andreazza, R. (2018). Análise ambiental e qualidade da água da lagoa dos patos nas proximidades de uma tradicional comunidade de pescadores. Revista Gestão \& Sustentabilidade Ambiental, 7(2), $105-123$. 
dos Santos, C. A. A. S., de Lucena, M. S., dos Santos Moraes, W., Silva, L. C., Silva, D. E. C., de Oliveira Serra, M. A. A., \& de Freitas Façanha Filho, P. (2020). Material compósito de argamassa e polímero: uma opção sustentável para a construção civil e reutilização de pneus inservíveis na cidade de Açailândia, Brasil. Research, Society and Development, 9(7), e538974591-e538974591.

dos Santos, N. B. C., dos Santos, R. H. G., \& da Silva, R. F. (2018). Aplicação da Análise Multivariada e da Resolução CONAMA 357/2005 para Análise da Qualidade de Água em Rios de Pernambuco (Application of Multivariate Analysis and Resolution CONAMA 357/2005 for Analysis of Water Quality in Rivers of Pernambuco). Revista Brasileira de Geografia Física, 11(5), 1859-1875.

Dumanski, J., \& Pieri, C. (2000). Land quality indicators: research plan. Agriculture, ecosystems \& environment, 81(2), 93-102.

Fernandes, L. L., \& Gois, R. V. (2015). Avaliação das Principais Metodologias Aplicadas às Análises Microbiológicas de Água para Consumo Humano Voltadas para a Detecção de Coliformes Totais e Termotolerantes. Revista Científica da Faculdade de Educação e Meio Ambiente, 6(2), $49-64$.

Ferrer, I., Zweigenbaum, J. A., \& Thurman, E. M. (2010). Analysis of 70 Environmental Protection Agency priority pharmaceuticals in water by EPA Method 1694. Journal of Chromatography A, 1217(36), 5674-5686.

Fonseca, F. R., \& Vasconcelos, C. H. (2011). Análise espacial das doenças relacionadas ao saneamento ambiental inadequado no Brasil. Cad Saúde Colet, 19(4), 448-53.

FUNASA. Fundação Nacional de Saúde (2013). Manual Prático de Análise de Água. (4a ed.), http://www.funasa.gov.br/site/wpcon tent/files_mf/manual_pratico_de_analise_de_agua_2.pdf

Griffith, J. F., Aumand, L. A., Lee, I. M., McGee, C. D., Othman, L. L., Ritter, K. J., ... \& Weisberg, S. B. (2006). Comparison and verification of bacterial water quality indicator measurement methods using ambient coastal water samples. Environmental monitoring and assessment, $116(1), 335-344$.

Guimarães, D. P., Pimenta, F. M., \& Landau, E. (2012). A integração Google Earth-SIG-Servidor de mapas e o monitoramento ambiental. Embrapa Milho $e$ Sorgo-Circular Técnica (INFOTECA-E). Disponível em: https://www.infoteca.cnptia.embrapa.br/bitstream/doc/953711/1/circ183.pdf

Jardim, W. F., \& Sodré, F. F. (2009). Desempenho analítico de laboratórios prestadores de serviço na determinação de metais em águas. Química Nova, 32(4), 1083-1088.

Kazi, T. G., Arain, M. B., Jamali, M. K., Jalbani, N., Afridi, H. I., Sarfraz, R. A., ... \& Shah, A. Q. (2009). Assessment of water quality of polluted lake using multivariate statistical techniques: A case study. Ecotoxicology and environmental safety, 72(2), 301-309.

Lima, J. A. D., Dambros, M. V. R., Antonio, M. A. P. M. D., Janzen, J. G., \& Marchetto, M. (2011). Potencial da economia de água potável pelo uso de água pluvial: análise de 40 cidades da Amazônia. Engenharia Sanitária e Ambiental, 16(3), 291-298.

Lopes, F. A., Silveira, J. S., Leite, A. C., Piazi, J., \& de Azevedo Lopes, N. I. (2019). Recreação de contato secundário em lagos urbanos: o caso da Lagoa da Pampulha. Revista GEOgrafias, 27(2), 42-60.

Marques, J. R. A., Nunes-Gutjahr, A. L., \& Braga, C. E. D. S. (2020). Situação sanitária e o uso da água do Igarapé Santa Cruz, município de Breves, Arquipélago de Marajó, Pará, Brasil. Engenharia Sanitaria e Ambiental, 25, 597-606.

Morais, R. C. D. S., \& Silva, C. E. D. (2012). Environmental diagnosis of Curva São Paulo bathing place at Poti river in Teresina city, Piauí, Brazil. Engenharia Sanitaria e Ambiental, 17(1), 41-50.

Neto, W. R. N., Pereira, D. C. A., Santos, J. R. N., Monteiro, A. S., Villis, P. C. M., \& Fillho, V. E. M. (2017). Análise da potabilidade das águas dos poços rasos escavados da comunidade do Taim em São Luís-Maranhão. Águas Subterrâneas, 31(3), 272-280.

Oliveira, T. F. D., \& Buss, D. F. (2018). Protocolo de avaliação da probabilidade de uso recreativo de rios e sua aplicação para análise de risco. Ciência \& Saúde Coletiva, 23, 3705-3717.

Parreira, A. G., \& Oliveira, R. A. (2017). Avaliação da qualidade microbiológica e físico-química da água consumida em escolas municipais de Divinópolis/MG. Revista Ibero-Americana de Ciências Ambientais, 8(2), 85-98.

Pereira, A. S., Shitsuka, D. M., Parreira, F. J., \& Shitsuka, R. (2018). Metodologia da pesquisa científica. UFSM. https://repositorio.ufsm.br/bitstream/handle/1/15824/Lic_Computacao_Metodologia-Pesquisa-Cientifica.pdf?sequence=1, 2018.

Ribeiro, T. I., Barros, F. D. A. A., \& Barros, S. B. A. (2021). Análise microbiológica de águas minerais de garrafões de 20 litros comercializada na cidade de Picos-PI. Brazilian Journal of Development, 7(2), 15487-15499.

Ribeiro, T. I., Barros, F. D. A. A., \& Barros, S. B. A. (2021). Análise microbiológica de águas minerais de garrafões de 20 litros comercializada na cidade de Picos-PI. Brazilian Journal of Development, 7(2), 15487-15499.

Rice, E. W., Baird, R. B., Eaton, A. D., \& Clesceri, L. S. (2012). APHA (American Public Health Association): Standard method for the examination of water and wastewater. Washington DC (US): AWWA (American Water Works Association) and WEF (Water Environment Federation).

Roewer, S. P., Nascimento, M. V. M., de Marchi, P. G. F., Lima, I. E., \& Duarte, L. M. (2016). Análise de indicadores microbiológicos da água para consumo humano no município de barra do Garças-MT. Revista Eletrônica Interdisciplinar, 1(15).

Röhnelt, N. M. S., da Silva Heck, T. M., Staggemeier, R., Almeida, S. E. D. M., \& do Nascimento, C. A. (2020). Vírus e microrganismos entéricos em balneários da bacia hidrográfica do Rio do Sinos-RS. COLÓQUIO-Revista do Desenvolvimento Regional, 17(3), 37-56.

Santos, G. P., Lopes, K. S. R., Schuh, A. J., de Lima, J. E. A., \& Holz, J. P. (2020). Análises De Ferro E Manganês Na Água Tratada De Porto Alegre/RS. Revista Gestão \& Sustentabilidade Ambiental, 9, 218-233. 
Research, Society and Development, v. 10, n. 13, e264101321080, 2021

(CC BY 4.0) | ISSN 2525-3409 | DOI: http://dx.doi.org/10.33448/rsd-v10i13.21080

Santos, V. O. (2010). Análise Físico-Química da água do rio Itapetininga-SP: Comparação entre dois pontos. Revista Eletrônica de Biologia (REB). ISSN 1983-7682, 3(1), 99-115.

Shrestha, S., \& Kazama, F. (2007). Assessment of surface water quality using multivariate statistical techniques: A case study of the Fuji river basin, Japan. Environmental Modelling \& Software, 22(4), 464-475.

Siqueira, L. P. D., Shinohara, N. K. S., Lima, R. M. T. D., Paiva, J. D. E. D., Lima Filho, J. L. D., \& Carvalho, I. T. D. (2010). Avaliação microbiológica da água de consumo empregada em unidades de alimentação. Ciência \& Saúde Coletiva, 15, 63-66.

Souza, J. R. D., Moraes, M. E. B. D., Sonoda, S. L., \& Santos, H. C. R. G. (2014). A importância da qualidade da água e os seus múltiplos usos: caso Rio Almada, sul da Bahia, Brasil. REDE-Revista Eletrônica do Prodema, 8(1).

Vidic, R. D., Brantley, S. L., Vandenbossche, J. M., Yoxtheimer, D., \& Abad, J. D. (2013). Impact of shale gas development on regional water quality. science, 340(6134).

Zhang, X., Yang, Z., \& Wang, Y. (2009, July). The Evaluation Method of Water Resources Utilazation Sustainbility: A Case Study of Tianjin. In 2009 International Conference on Environmental Science and Information Application Technology (Vol. 3, pp. 158-161). IEEE.

Zoby, J. L. G. (2008). Panorama da qualidade das águas subterrâneas no Brasil. Águas Subterrâneas. 